\title{
A PROTEÇÃO MULTINÍVEL DO DIREITO À SAÚDE SOB A ÓTICA DO SUPREMO TRIBUNAL FEDERAL E DA CORTE INTERAMERICANA DE DIREITOS HUMANOS: ANÁLISE COMPARATIVA
}

\author{
THE MULTILEVEL PROTECTION OF RIGHT TO HEALTH FROM THE PERSPECTIVE \\ OF THE BRAZILIAN FEDERAL SUPREME COURT AND THE INTER-AMERICAN \\ COURT OF HUMAN RIGHTS: A COMPARATIVE ANALYSIS
}

Recebido: 05.01.2020

Aprovado: 14.03 .2020

\begin{abstract}
Maria Valentina de Moraes
Doutoranda pela UNISC. Bolsista PROSUC/CAPES. Membro do Grupo de Pesquisa "Jurisdição Constitucional aberta: uma proposta de discussão da legitimidade e dos limites da jurisdição constitucional instrumentos teóricos e práticos", vinculado ao $\mathrm{CNPq}$ e coordenado pela professora Pós-Dr ${ }^{\mathrm{a}}$ Mônia Clarissa Hennig Leal.

EMAIL: mariavalentina.23@hotmail.com.

LATTES: $\quad$ http://lattes.cnpq.br/2400734786644430. ORCID: https://orcid.org/0000-0002-8298-5645
\end{abstract}

\section{Flávia Thais Stein}

Mestranda pela UNISC. Bolsista PROSUC/CAPES. Membro do Grupo de Pesquisa "Jurisdição Constitucional aberta: uma proposta de discussão da legitimidade e dos limites da jurisdição constitucional instrumentos teóricos e práticos", vinculado ao $\mathrm{CNPq}$ e coordenado pela professora Pós-Dr ${ }^{\mathrm{a}}$ Mônia Clarissa Hennig Leal.

EMAIL: flah.stein@hotmail.com.

LATTES: http:/ / lattes.cnpq.br/7370796296241399

ORCID: https://orcid.org/0000-0001-8532-3404

\begin{abstract}
RESUMO: O fenômeno da judicialização da saúde vem apresentando-se como uma constante no ordenamento jurídico brasileiro por meio de diversas demandas buscando a concretização desse direito fundamental social em nível nacional. A proteção internacional destinada aos direitos sociais, por outro lado, ainda é objeto de construção doutrinária e jurisprudencial, especialmente na América Latina. Utilizando-se do método dedutivo e do método de procedimento comparativo, questionam-se quais são as diferenças na tutela do direito à saúde na jurisdição nacional (Supremo Tribunal Federal) e internacional (Corte Interamericana de Direitos Humanos). Assim, após análise do fenômeno da judicialização e dos aspectos que cercam a construção do direito à saúde como um direito público subjetivo, são trazidos aspectos acerca do Sistema Interamericano de Proteção e do controle de convencionalidade, bem como a discussão sobre como a ordem internacional - em especial a Corte Interamericana de Direitos Humanos - vem se posicionando sobre o tema. É possível analisar, desse modo, que a alargada tutela do direito fundamental social à saúde no Brasil não apresenta-se como uma tendência internacional, sendo inexistentes julgamentos por parte da Corte de San José sobre a questão, ainda que a mesma detenha competência para analisar pactos onde direitos classificados como sociais são garantidos.
\end{abstract}

PALAVRAS-CHAVES: Análise comparativa; Corte Interamericana de Direitos Humanos; judicialização da saúde; proteção multinível; Supremo Tribunal Federal. 


\begin{abstract}
The phenomenon of the judicialization of health has been presenting itself as a constant in the Brazilian legal system through several demands seeking the realization of this fundamental social right at the national level. International protection for social rights, on the other hand, is still subject to doctrinal and jurisprudential construction, especially in Latin America. Using the deductive method and the method of comparative procedure, we question the differences in the protection of the right to health in the national jurisdiction (Supreme Court) and international (Inter-American Court of Human Rights). Thus, after analyzing the phenomenon of judicialization and the aspects that surround the construction of the right to health as a subjective public right, aspects are brought about the Inter - American System of Protection and the control of conventionality, as well as the discussion about how the international order - in particular the Inter-American Court of Human Rights - has been positioning itself on the subject. It is possible to analyze, therefore, that the extended protection of the fundamental social right to health in Brazil does not present itself as an international tendency, and there are no judgments on the part of the Court of San José on the matter, although it has the competence to analyze pacts where rights classified as social are guaranteed.
\end{abstract}

KEY WORDS: Comparative analysis; Inter-American Court of Human Rights; judicialization of right to health; multilevel protection; Brazilian Federal Supreme Court.

SUMÁRIO: 1 Introdução 2 Direito à saúde como direito público, fundamental e social: Aspectos conceituais $3 \mathrm{O}$ fenômeno da Judicialização da saúde no Brasil como reflexo da tutela subjetiva dos direitos fundamentais sociais 4 Sistema Interamericano de Proteção de Direitos Humanos: Aspectos teóricos acerca do controle de convencionalidade 5 A tutela do direito à saúde em nível internacional: efetivação jurisprudencial? 6 Conclusão 7 Referências

\title{
1 Introdução
}

O fortalecimento e a constitucionalização dos direitos fundamentais sociais a nível mundial decorrem especialmente do cenário pós Segunda Guerra Mundial. No Brasil, é com a Constituição Federal de 1988 que se dá o reconhecimento do caráter fundamental desses direitos, os quais, aliados à noção de direitos fundamentais como mandamentos de otimização e diante do reconhecimento da existência das dimensões objetiva e subjetiva desses, passam a ocupar a pauta judicial do país de forma mais recorrente. A possibilidade de tutela individualizada dos direitos fundamentais sociais é aceita pela maior parte da doutrina e vem sendo reforçada pela jurisprudência dos tribunais.

A noção de centralidade da Constituição, a realização de um controle de constitucionalidade das normas e o protagonismo do Poder Judiciário no Estado Democrático de Direito são características que se apresentam em um contexto como o vivido nos dias de hoje, resultando em uma crescente judicialização dos direitos sociais - e aqui, volta-se o olhar especialmente para a judicialização do direito à saúde. A tutela desse direito e sua concretização, por meio de políticas públicas ou de forma individual, é recorrente na jurisdição brasileira, adotando o mais alto Tribunal brasileiro um posicionamento no sentido de efetivação do direito à saúde.

Já em nível interamericano, embora a crescente em termos de condenações da Corte Interamericana de Direitos Humanos e de processos levados à jurisdição internacional, não há qualquer julgamento que abarque de forma específica o direito à saúde - ainda que este esteja assegurado em instrumentos internacionais. Em razão dessas diferenças, cabe questionar, utilizando o método dedutivo e o método de procedimento comparativo, quais são as diferenças 
na tutela do direito à saúde na jurisdição nacional (Supremo Tribunal Federal) e internacional (Corte Interamericana de Direitos Humanos).

Para tanto, em um primeiro momento será realizada uma análise dos aspectos que cercam a construção do direito à saúde como um direito público subjetivo, de caráter fundamental, e do fenômeno da judicialização para, após, apresentar aspectos acerca do Sistema Interamericano de Proteção e do controle de convencionalidade, bem como a discussão sobre como a ordem internacional - em especial a Corte Interamericana de Direitos Humanos vem se posicionando em termos de proteção de direitos fundamentais sociais, com ênfase na proteção do direito fundamental social à saúde. Importante, assim, compreender os elementos que identificam o direito à saúde e o colocam em posição de análise.

\section{DIREITO À SAÚdE COMO DIREITO PÚBLICO, FUNDAMENTAL E SOCIAL: ASPECTOS CONCEITUAIS}

Após a Segunda Guerra Mundial, o mundo inteiro ficou atônito com as atrocidades praticadas durante a grande guerra e começaram questionar as condições humanas e a necessidade de garantia efetiva dos direitos humanos, sendo que os Estados viram-se obrigados a reconhecer os direitos sociais. O movimento para garantia dos direitos humanos iniciou com a criação das Nações Unidas (ONU) e, no caso do direito à saúde, a ONU incentivou a criação de órgãos que protegessem o direito social à saúde, sendo criada a OMS - Organização Mundial da Saúde ${ }^{1}$

Seguindo as orientações, as Constituições europeias do pós-guerra afirmaram constitucionalmente o direito à saúde. O Brasil sofreu tardiamente os efeitos referentes aos direitos sociais, sendo que as constituições de 1891 e 1824 já mencionavam o direito à saúde. Entretanto, a Constituição Federal de 1988 foi a primeira dentre as constituições brasileiras a garantir o direito à saúde no rol dos direitos fundamentais ${ }^{2}$. Nesse sentido, o direito à saúde como condição digna de vida e bem estar social, está intimamente ligado ao direito fundamental da dignidade da pessoa humana, sendo que está expresso na Constituição Federal brasileira no art. $6^{\circ}$ como Direito Social. ${ }^{3}$

A Constituição, no Título II, em seu segundo capítulo, trata dos Direitos Sociais como direitos prestacionais, trazendo em seu artigo 6 o que: "São direitos sociais a educação, a saúde, o trabalho, a moradia, o lazer, a segurança, a previdência social, a proteção à maternidade e à infância, a assistência aos desamparados, na forma desta Constituição" (grifo nosso). Este direito social não é simplesmente uma norma pragmática, sendo regulamentado por meio do estabelecimento expresso de deveres do Estado e, consequentemente, de direitos subjetivos dos indivíduos. ${ }^{4}$

Diante do conceito positivado na Constituição Federal de 1988, restou evidente que o Estado está incumbido da prestação material e efetivação desse direito, conforme abaixo transcrevemos:

1 CARVALHO, Mariana Siqueira de Carvalho. A Saúde como direito Social Fundamental na Constituição Federal De 1988. Revista de Direito Sanitário, Brasília - DF, v. 4, n. 2, jul. 2003.

2 (Ibidem, 2003, p. 23)

3 PRADO, Ana Paula Barroso de Salles Paiva. Direito fundamental à saúde: direito social tratado como direito individual no Brasil. Tese (Mestrado em Direito) - Faculdade de Direito do sul de Minas. Pouso Alegre - MG. 2012. p. 56.

4 KRELL, Andreas Joachim. Realização dos direitos fundamentais sociais mediante controle judicial da prestação dos serviços públicos básicos (uma visão comparativa). Brasília a. 36 n. 144 out./dez. 1999. p. 239-260. p. 241.

139 | Revista do Programa de Pós-Graduação em Direito da UFBA, e-issn 2358-4777, v. 30, n. 01, p.137 -150, Jan-Jun 2020 
Art. 196. A saúde é direito de todos e dever do Estado, garantido mediante políticas sociais e econômicas que visem à redução do risco de doença e de outros agravos e ao acesso universal e igualitário às ações e serviços para sua promoção, proteção e recuperação.

Nesse sentido, o direito à saúde restou expressamente positivado na Constituição Federal brasileira de 1988 nos art. 196 a 200. Com isso, o direito à saúde se constitui em um direito público e subjetivo, exigindo do Estado a sua efetivação. ${ }^{5} \mathrm{~A}$ não efetivação do direito à saúde caracteriza-se como um inaceitável desrespeito ao direito à vida, pois sem saúde restam comprometidos os direitos fundamentais da dignidade humana, bem como a autonomia e a autodeterminação. ${ }^{6}$ É neste compasso que o direito fundamental e social à saúde deve ser visto, protegido e aplicado, não só enquanto direito individual e direito coletivo, mas também, sob a égide de um direito em construção, de um direito por vir. ${ }^{7}$

Nesse sentido, o direito social à saúde, bem como seu acesso, surge com o intuito de preservação e de proteção à saúde, sendo concebido como um direito de todos e dever do Estado, o qual deve garantir mediante políticas sociais e econômicas e a oferta de serviços públicos que visem preservar e proteger a vida do cidadão. Com a Constituição de 1988 o direito à saúde foi considerado como direito subjetivo público, tendo em vista o reconhecimento de que o cidadão é detentor do direito e o Estado tem a obrigação de fornecê-lo, da mesma forma a responsabilidade própria do sujeito em cuidar de sua própria saúde e colaborar para saúde coletiva. ${ }^{8}$ Diante desse caráter, alguns fenômenos envolvendo outros elementos do Estado Democrático de Direito, como a judicialização da saúde colocaram novamente a efetivação desse direito fundamental social em debate, sendo necessário compreender os aspectos que a condicionam.

\section{O FENÔMENO DA JUDICIALIZAÇÃO DA SAÚDE NO BRASIL COMO REFLEXO DA TUTELA SUBJETIVA DOS DIREITOS FUNDAMENTAIS SOCIAIS}

O fenômeno da judicialização da saúde está em plena expansão no Brasil, uma vez que crescem as demandas que chegam ao Poder Judiciário buscando a efetivação dos direitos fundamentais à pessoa humana ${ }^{9}$, sendo o principal deles o direito à saúde. O Estado Constitucional de Direito começa a adquirir força a partir da $2^{\circ}$ Guerra Mundial, passando a Constituição daí possuir força como norma jurídica. Nesse novo modelo, vigora a centralidade da Constituição e a supremacia judicial, como tal entendida a primazia de um Tribunal Constitucional ou Suprema Corte na interpretação final e vinculante das normas constitucionais. ${ }^{10}$

5 PRADO, 2012, p. 50.

6 RODRIGUEIRO, Daniela Aparecida; MOREIRA, José Cláudio Domingues. O direito social à saúde na perspectiva da constituição de 1988: um direito individual, coletivo e em construção. RIPE - Revista do Instituto de Pesquisas e Estudos, Bauru, v.50, n.66, p.143-159, jul./dez. 2016, p. 148.

(RODRIGUEIRO E MOREIRA, 2016, p. 149).

(Ibidem, 2012, p. 109).

9 Também sob o argumento da realização de um controle jurisdicional de políticas públicas é possível perceber que a natureza das decisões segue possuindo caráter individual, como constatado em pesquisa realizada no sítio eletrônico do Supremo Tribunal Federal, no período compreendido entre 2009 e 2016 sendo também monitorados os anos seguintes, na qual foram analisadas 55 (cinquenta e cinco) decisões envolvendo a prestação de direitos sociais, em sua maioria, o direito fundamental social à saúde.

10 BARROSO, Luís Roberto. Constituição, democracia e supremacia judicial: direito e política no brasil 140 | Revista do Programa de Pós-Graduação em Direito da UFBA, e-issn 2358-4777, v. 30, n. 01, p.137 -150, Jan-Jun 2020 
Nesse sentido, a Constituição cada vez mais se empodera, visto que limita o poder político e institui maior rigidez as normas, passando os Tribunais Superiores a decidirem questões de relevante interesse social em nome da Lei Fundamental. Passando os mesmos a pertencerem ao processo político, na medida em que o conduzem, assim como também são conduzidos por esse processo. $^{11}$

No Brasil, esse processo de judicialização do direito é exercício pelos Juízes e pelos Tribunais, tendo o Supremo Tribunal Federal papel ativo e decisivo nas decisões relativas aos direitos fundamentais e na concretização da Constituição. Por conseguinte, a jurisdição constitucional, que é a interpretação e aplicação das normas constitucionais pelo Poder Judiciário, compreende o poder exercido por juízes e tribunais na aplicação direta da Constituição, no desempenho do controle de constitucionalidade das leis e dos atos do Poder Público em geral e na interpretação do ordenamento infraconstitucional conforme a Constituição. ${ }^{12}$

Dessa forma, a inter-relação entre Direito e Política, entre função jurisdicional e função política, torna-se ínsita a essa Constituição, sendo essa separação apenas institucional, visto que, como a tarefa de todos os Poderes é resguardar a Lei Fundamental, garantir os direitos fundamentais, não teriam como agir separados ou um oposto ao outro, mas em conjunto. ${ }^{13}$ Destarte, o constitucionalismo democrático prioriza o respeito aos direitos fundamentais, a democracia, a soberania popular e o governo da maioria. Mas pode acontecer de a maioria política questionar os direitos fundamentais. Quando isto ocorre, cabe ao Judiciário agir. ${ }^{14}$ Os direitos de grupos minoritários também devem ser resguardados.

Os direitos fundamentais à pessoa humana apareceram na normativa brasileira com a Constituição de 1988, denominada "Constituição cidadã", haja vista a grande disponibilidade de direitos e garantias fundamentais, facilitando o acesso a esses direitos através do Poder Judiciário. Nesse caminho, a judicialização dos direitos fundamentais possui como principal característica o protagonismo do Poder Judiciário, sendo a judicialização a decisão, em caráter final, de questões relevantes e sociais, política ou moralmente, pelas Cortes Superiores.

O fenômeno da judicialização dos direitos faz com que o direito, cada vez mais, seja um direito jurisdicional, construído pelos magistrados, e não pelo Legislativo, tornando-o um direito jurisprudencial. No Brasil, esse processo ganha ainda mais importância, no sentido que o Poder Legislativo é, muitas vezes, omisso em relação às questões de relevância política, social ou moral, e temas de grande repercussão social; dessa forma, restam para o Poder Judiciário a decisão da questão, no momento em tais questões estão postas em sede judicial, uma vez que o Poder Judiciário não pode esquivar-se da decisão. Muitas críticas se apresentam, nesse sentido, à eventual protagonismo judicial, que pode gerar uma supremacia deste poder em relação aos demais. $^{15}$

contemporâneo. RFD- Revista da Faculdade de Direito- UERJ, v. 2, n. 21, jan./jun. 2012, p. 04.

11 MAAS, Rosana Helena Maas. O dever dos entes estatais de disponibilizar informações públicas como fundamento para o exercício do status activus processualis no controle de políticas públicas: uma proposta de canal de informação e transparência em políticas públicas da saúde (CITAPP saúde) frente ao estudo da judicialização da saúde em Santa Cruz do Sul. 2016. 289f. Tese (Programa de Pós-Graduação em Direito Mestrado e Doutorado) - Universidade de Santa Cruz do Sul, Santa Cruz do Sul, 2016., p. 23).

12 (Ibidem, 2012, p. 04).

13 (Ibidem, 2016, p. 21).

(Ibidem, 2012, p. 15).

15 STEIN, Flávia Thais; MORAES, Maria Valentina. Jurisdição constitucional e direitos fundamentais sociais: o problema da judicialização da saúde no município de Sobradinho. XIV Seminário Nacional de demandas sociais e políticas públicas na sociedade contemporânea \& IV Mostra nacional de trabalhos científicos. Universidade de Santa Cruz do Sul, 2018. Disponível em: < https://online.unisc.br/acadnet/anais/index.php/snpp/article/viewFile/17969/1192611938> Acesso em: 20

141 | Revista do Programa de Pós-Graduação em Direito da UFBA, e-issn 2358-4777, v. 30, n. 01, p.137 -150, Jan-Jun 2020 
Com efeito, a judicialização decorre, sobretudo, do modelo de constitucionalização abrangente, haja vista a grande disponibilidade de direitos e garantias previstas na Constituição Brasileira e o sistema de controle de constitucionalidade vigente, permitindo facilitado acesso das demandas ajuizadas aos Tribunais Superiores. ${ }^{16}$

Em função disso, percebe-se que a aplicação do próprio direito exige a uma postura mais ativa do Poder Judiciário, sendo que e a Constituição veda de forma explícita, a redução de direitos fundamentais inerentes à pessoa humana. Dessa forma, a partir da Constituição de 1988, passa-se a ser "comum" o crescente grau de judicialização de direitos fundamentais, incumbindo ao Poder Judiciário decidir sobre direitos indisponíveis, inclusive e principalmente sobre o direito fundamental à saúde. Em uma perspectiva de proteção de direitos de forma individualizada por meio da judicialização, destaca Friedman ${ }^{17}$ :

if the governmental action affected a number of individuals, a number of separate adjudications may ensue. There may be conflicting decisions. Several jurisdictions and many judges will be involved. If the issue is of general importance the Supreme Court may hear the case. At this point in the process, an issue, not just a case, is clearly being debated. The Court will hear argument about the issue, which will have be entailored throughout the litigation by the process of win nowing and synthesizing. Groups that might be affected will file their own brief sand will of fer help to the parties. Debate is sharpened.

A importância da atuação da jurisdição nacional na promoção de direitos é inegável ainda que questionáveis os limites da mesma. Após o reconhecimento da jurisdição da Corte Interamericana de Direitos Humanos a mesma ganha um reforço na proteção de direitos humanos, dentre eles o direito social à saúde, que pode ser objeto do controle de convencionalidade, como será analisado.

\section{SISTEMA INTERAMERICANO DE PROTEÇÃO DE DIREITOS HUMANOS: ASPECTOS TEÓRICOS ACERCA DO CONTROLE DE CONVENCIONALIDADE}

A criação de uma ordem internacional de proteção de direitos humanos - que decorre em grande medida dos muitos tratados internacionais que pretendiam unificar a proteção desses direitos - reforça a proteção estatal até então destinada a eles. Tem-se configurado, assim, um "sistema de derechos humanos multinivel - constitucional, internacional regional e internacional universal -[que] configura un sistema único coherente de protección de los derechos humanos" ${ }^{18}$. De um controle de legalidade das normas, passa-se a preocupação com o conteúdo das mesmas em relação à Constituição Federal, o que é ampliado e passa a abranger os tratado e normas internacionais, dando origem ao controle de convencionalidade das normas.

A criação dos Sistemas de Proteção de Direitos Humanos reforça também o

Ago. 2019, p. 05

16 (Ibidem, 2012, p. 05).

17 FRIEDMAN, Barry. Dialogue and judicial review. The Michigan Law Review Association, Michigan, v. 91, p. 577-682, 1993. p. 655.

18 CAVALLO, Gonzalo Aguilar. El juez estatal en la era del constitucionalismo de los derechos. In: LEAL, M. C. H.; ALVES, F. D. (Orgs.). Diálogos continentais sobre o controle de convencionalidade. Curitiba: Prismas, 2017.

142 | Revista do Programa de Pós-Graduação em Direito da UFBA, e-issn 2358-4777, v. 30, n. 01, p.137 -150, Jan-Jun 2020 
constitucionalismo multinível, estando a Corte Interamericana no centro da proteção regional desses direitos. O reconhecimento da jurisdição da Corte IDH - realizado pelo Brasil apenas no ano de 1998, com o decreto no. 4.463 no ano de 2002, sendo a Convenção Americana datada de 1969 e tendo entrado em vigor em 1978 e ratificada pelo Brasil no ano de 1992, por meio do Decreto n. 678 -, que ocorre de forma voluntária, consolidou e vem consolidando essa forma de controle. A teoria do controle de convencionalidade, jurisprudencialmente, origina-se com,

el hoy ex presidente de la Corte IDH, Sergio García Ramíres, en su voto concurrente razonado emitido en el caso Myrna MackChange $c$. Guatelama, quien en el marco de ese Tribunal supraestatal utilizó por vez primera la expresión control de convencionalidad que trae consigo la jurisdicción de la Corte. [...] ya con mayor grado de detalle y por medio de un voto concurrente razonado en el caso Tibi c. Ecuador, explicó que el Tribunal Interamericano analiza los actos que llegan a su conocimiento en relación con normas, principios y valores de los tratados en los que funda su competencia contenciosas, resolviendo acerca de la convencionalidad de tales actos, pretendiendo <confirmar esa actividad al orden internacional acogido en la convención fundadora de la jurisdicción interamericana y aceptado por los Estados partes en ejercicio de su soberanía $>>^{\prime 19}$.

Têm-se, com a possibilidade deste controle de convencionalidade, uma internacionalização dos direitos até então nacionais, convertendo-se a Constituição em um documento flexível que se adapta a evolução da proteção destinada aos direitos humanos em nível internacional ${ }^{20}$. A Constituição não se encontra mais restrita apenas ao plano nacional, passando a contemplar a possibilidade de adequação de seu conteúdo a uma ampla garantia internacional de direitos humanos. A Corte Interamericana de Direitos Humanos, enquanto um dos principais órgãos do Sistema Interamericano de Proteção - juntamente, no caso interamericano, com a Comissão Interamericana de Direitos Humanos - passa a ser a responsável pela análise das violações cometidas pelos Estados. A evolução da proteção destes direitos na atuação da Corte de San José da Costa Rica é referida por Arroyo ${ }^{21}$, que destaca que

en una primera hora de protección de la Corte IDH, las resoluciones que ella expidió estaban vinculadas a la protección de derechos humanos de primera generación; es decir, se trataba de condenas a los Estados y disposiciones de reparación [...] a las víctimas de las violaciones al derecho a la vida, la integridad personal, la libertad personal, entre otros. En una segunda hora, la Corte IDH viene resolviendo causas que son mayoritariamente referidas a las violaciones de los derechos al debido proceso legal, libertad, propiedad, libertad expresión, nacionalidad, entre otros.

19 BAZÁN, Víctor. El control de convencionalidad: incógnitas, desafíos y perspectivas. In: BAZÁN, Víctor; NASH, Claudio. Justicia Constitucional y Derechos Fundamentales: El control de convencionalidad. Colombia: Unión Gráfica Ltda, 2012. p. 17-55. p. 25, grifado no original.

20 LEDESMA, Eréndira Salgado. La problable inejecución de las sentencias de la Corte Interamericana de Derechos Humanos. Cuestiones Constitucionales: Revista Mexicana de Derecho Constitucional. México, 2012, p. 221-260. p. 229.

21 ARROYO, César Landa. Convencionalización del Derecho peruano. Lima: Palestra, 2016. p. 37.

143 | Revista do Programa de Pós-Graduação em Direito da UFBA, e-issn 2358-4777, v. 30, n. 01, p.137 -150, Jan-Jun 2020 
O controle de convencionalidade, em suas primeiras referências, possui como elementos centrais "en primer lugar, y acertadamente, la unidad del Estado ante el DIP; en segundo lugar, la existencia, derivada de la jurisdicción de la Corte, de un control de convencionalidad, al que se encuentra obligado ella y toda autoridad nacional"22. O Estado não se configura mais como o único a proteger direitos, estendendo-se a proteção até então apenas constitucional, ao nível internacional. Se não realizado por tribunais internos com base na Constituição Federal ou em tratados de direito internacional, detém a Corte Interamericana tal prerrogativa, em caráter subsidiário.

Já a realização do controle de convencionalidade em nível interno é, por sua vez, construída na decisão do Caso Almonacid Arellano e outros versus Chile, de 2006, afirmando a Corte Interamericana de Direitos Humanos a obrigatoriedade de que os Estados também verifiquem a compatibilidade - convencionalidade - de suas normas com a Convenção Americana de Direitos Humanos (CADH) e demais tratados internacionais que compõem o corpus iures interamericano ${ }^{23}$. Com a realização também em nível nacional deste controle é necessária "una articulación de tal binomio de fuentes mediante retroalimentación y complementariedad"24 entre os ordenamentos, a fim de garantir uma maior e melhor proteção de direitos.

Pode-se dizer que a Corte Interamericana de Direitos Humanos encontra-se, nesse contexto, "a la vanguardiaen la evolución de la protección internacional, en especial por convertir los tribunales constitucionales en auxiliares suyos" ${ }^{\prime 25}$, estendendo o alcance do controle de convencionalidade. Também os juízes nacionais e as demais autoridades públicas passam a ter como dever a realização do controle de convencionalidade por meio da verificação da adequação das normas internas aos os direitos assegurados na Convenção Americana de Direitos Humanos (CADH), principal instrumento do Sistema ${ }^{26}$ e, ainda "a los patrones interpretativos que el Tribunal Interamericano ha acuñado a su respecto, en aras de la cabal tutela de los derechos básicos" 27 .

Assim, não apenas a Corte Interamericana, mas também os juízes nacionais devem interpretar as normas internacionais, concretizando "el control de convencionalidad cuando concretan la aplicación preferente de la convención sobre la legislación interna" ${ }^{28}$, quando a proteção interamericana destinada aos direitos envolvidos for maior que a nacional. Desse modo, é possível afirmar que "posibilidades de éxito de la tesis del control de convencionalidad

22 CASAL, María Angélica Benavides. El control de compatibilidad y el control de convencionalidad (o el problema de la competencia). Estudios Constitucionales: Revista del Centro de Estudios Constitucionales, Talca, Ano 15, no. 2. p. 365-388, 2017. p. 370, grifado no original.

23 ALCALÁ, Humberto Nogueira. El uso de las comunicaciones transjudiciales por parte de las jurisdicciones constitucionales en el derecho comparado y chileno. In: ALCALÁ, H. N.; ZELADA, L. G. Jurisprudencia del Tribunal Constitucional ante los derechos humanos y el derecho constitucional extranjero. Santiago: Librotecnia, 2014. p. 509-570. p. 510.

24 BAZÁN, Víctor. El control de convencionalidad: incógnitas, desafíos y perspectivas. In: BAZÁN, Víctor; NASH, Claudio. Justicia Constitucional y Derechos Fundamentales: El control de convencionalidad. Colombia: Unión Gráfica Ltda, 2012. p. 17-55. p. 19.

25 USERA, Raúl Canosa. El Control de Convencionalidad. Pamplona: Aranzadi, 2015. p. 16.

26 BAZÁN, Víctor. El control de convencionalidad: incógnitas, desafíos y perspectivas. In: BAZÁN, Víctor; NASH, Claudio. Justicia Constitucional y Derechos Fundamentales: El control de convencionalidad. Colombia: Unión Gráfica Ltda, 2012. p. 17-55. p. 14.

27 BAZÁN, Víctor. El control de convencionalidad: incógnitas, desafíos y perspectivas. In: BAZÁN, Víctor; NASH, Claudio. Justicia Constitucional y Derechos Fundamentales: El control de convencionalidad. Colombia: Unión Gráfica Ltda, 2012. p. 17-55. p. 24.

28 ALCALÁ, Humberto Nogueira. El uso de las comunicaciones transjudiciales por parte de las jurisdicciones constitucionales en el derecho comparado y chileno. In: ALCALÁ, H. N.; ZELADA, L. G. Jurisprudencia del Tribunal Constitucional ante los derechos humanos y el derecho constitucional extranjero. Santiago: Librotecnia, 2014. p. 509-570. p. 528.

144 | Revista do Programa de Pós-Graduação em Direito da UFBA, e-issn 2358-4777, v. 30, n. 01, p.137 -150, Jan-Jun 2020 
están cifradas em el grado de receptividad de esta em los derechos internos, la labor de los respectivos operadores jurídicos involucrados y la voluntad política" dos Estados ${ }^{29}$, uma vez que não há qualquer sanção ao incumprimento das decisões interamericanas.

É necessário, para tanto, que os juízes nacionais conheçam o bloco de direitos humanos e também a jurisprudência da Corte de San José ${ }^{30}$, a qual, como referido, também possui caráter vinculante aos Estados. Como referido anteriormente, a jurisprudência da Corte apresenta muitos elementos que podem enriquecer a jurisprudência nacional, principalmente no que toca à questão conceitual, sendo de suma importância analisar como - e se - a mesma vem se posicionando em termos de direitos fundamentais e sociais protegidos na ordem nacional. Passa-se, portanto, à análise da atuação da Corte Interamericana de Direitos Humanos no que tange ao direito à saúde.

\section{A TUTELA DO DIREITO À SAÚDE EM NÍVEL INTERNACIONAL: EFETIVAÇÃO JURISPRUDENCIAL?}

A Constituição brasileira, como referido, é clara em estabelecer a proteção do direito à saúde enquanto direito social, bem como defini-lo como dever do Estado, garantido por meio de políticas públicas de ordem social e econômica. No Sistema Interamericano de Proteção de Direitos Humanos, por outro lado - e embora existente a noção de uma proteção multinível de direitos -, os direitos sociais não possuem sua tutela garantida perante a Corte Interamericana de Direitos Humanos, que, ao lado da Comissão e demais atores e tratados internacionais, compõem referido Sistema ${ }^{31}$. É interessante, neste contexto, apontar a distinção conceitual no que toca aos direitos fundamentais e humanos, que embora radiquem na proteção da dignidade humana, são tratados de forma distinta em nível nacional e internacional, não existindo uma unanimidade conceitual $\left.\right|^{32}$.

É, nesse sentido, "frecuente la propensión a contemplar toda libertad jurídicamente protegida como um derecho fundamental"33, sendo um dos principais aspectos que diferenciam os direitos chamados fundamentais dos chamados humanos o fato de que os primeiros possuem maior relação com o ordenamento nacional e ostentam a condição de positivados, a medida em que os segundos são de caráter internacional e natural ${ }^{34}$. Alexy e Silva ${ }^{35}$ alertam, contudo, para o fato de que o caráter positivo é apenas uma das faces que identifica dos direitos fundamentais, os quais possuem também uma dimensão ideal.

O direito à saúde, enquanto direito de natureza fundamental, é reconhecido também em muitos tratados internacionais dos quais o Brasil é signatário. Todavia, a Convenção Americana sobre Direitos Humanos, principal instrumento internacional em nível interamericano, não

29 BAZÁN, Víctor. El control de convencionalidad: incógnitas, desafíos y perspectivas. In: BAZÁN, Víctor; NASH, Claudio. Justicia Constitucional y Derechos Fundamentales: El control de convencionalidad. Colombia: Unión Gráfica Ltda, 2012. p. 17-55. p. 52.

30 BAZÁN, Víctor. El control de convencionalidad: incógnitas, desafíos y perspectivas. In: BAZÁN, Víctor; NASH, Claudio. Justicia Constitucional y Derechos Fundamentales: El control de convencionalidad. Colombia: Unión Gráfica Ltda, 2012. p. 17-55. p. 25.

31 ARROYO, César Landa. Convencionalización del Derecho peruano. Lima: Palestra, 2016. p. 66.

32 GORCZEVSKI, Clovis. Direitos Humanos, Educação e Cidadania: conhecer, educar, praticar. 2. ed. Santa Cruz do Sul: Edunisc, 2016. p. 26.

33 GRIMM, Dieter. Constitucionalismo y derechos fundamentales. Madrid: Trotta, 2006. p. 77.

34 ALCALÁ, Humberto Nogueira. Teoria de los derechos fundamentales y los derechos humanos. Montevideo: Ingranusi, 2000. p. 39.

35 ALEXY, R.; SILVA, R. L. N. Direitos fundamentais sociais e proporcionalidade. In: ALEXY, R.; XAVIER, N. L.; SILVA, R. L. N. D. Dignidade humana, direitos sociais e não-positivismoinclusivo. Florianópolis: [s.n.], 2015. p. 165-178. p. 167.

145 | Revista do Programa de Pós-Graduação em Direito da UFBA, e-issn 2358-4777, v. 30, n. 01, p.137 -150, Jan-Jun 2020 
abarca, em seu conteúdo, a proteção direta de direitos econômicos, sociais e culturais. A inclusão dessa proteção foi objeto de debate pelo Conselho Interamericano quando da elaboração da Convenção Americana sobre Direitos Humanos, como estacada Trindade:

a pesar de las propuestas de inserción de derechos económicos, sociales y culturales em el proyecto de Convención presentadas en 1959 por el Consejo Interamericano de Jurisconsultos y en 1965 por Chile y Uruguai, el sistema interamericano de protección de los derechos humanos seguió la solución de los modelos mundiales y europeo ${ }^{36}$.

O caráter programático das normas de direitos sociais, constitucionalizadas no Brasil, que foi objeto de debate nacionalmente, é existente em certa medida também na Convenção Americana, dificultando posicionamentos mais firmes e estruturantes nesse sentido. $\mathrm{Na}$ Convenção Americana tal referência aparece com a ideia de "desenvolvimento progressivo", como destacam Piovesan e De Freitas ${ }^{37}$ :

muito embora seja frequentemente utilizada como fundamento para demandas que envolvam direitos sociais carentes de ações afirmativas, a Convenção, em verdade, dedicou inicialmente aos direitos econômicos, sociais e culturais - DESC - tão somente uma menção em cláusula normativa, constante do art. 26, intitulada de "desenvolvimento progressivo".

Ainda que a jurisprudência da Corte de San José venha sendo cada vez mais conhecida em termos de proteção a direitos humanos, os direitos de caráter social ainda estão marginalizados em termos argumentativos e condenatórios, refletindo uma postura habitual em âmbito internacional. É possível perceber que "prácticas discriminatórias son hace mucho tiempo condenadas em relación a los derechos políticos, pero persisten y son toleradas como lamentables 'realidades' em relación com los derechos económicos, sociales y culturales" ${ }^{138}$. 0 caráter das demandas levadas à Corte na América Latina torna-se um ponto a ser considerado nesse cenário, uma vez que refletem, em grande medida, violações imediatamente relacionadas ao direito à vida ${ }^{39}$.

Este déficit em termos de proteção dos direitos econômicos, sociais e culturais não é recente na ordem externa. A própria criação de dois pactos distintos (Pacto Internacional sobre Direitos Econômicos Sociais e Culturais e Pacto Internacional sobre Direitos Civis e Políticos) para a proteção desses reflete a dificuldade dos Estados em assumirem obrigações internacionais quanto aos direitos sociais, uma vez que "puede afirmarse que la distinción entre derechos

36 TRINDADE, Antonio Augusto Cançado. La protección internacional de los derechos económicos, sociales y culturales. In: CRUZ, R. C.; LOAIZA, R. N. Estudios básicos de derechos humanos. San José: IIDH, 1994, p. 3962. p. 3.

37 PIOVESAN, Flavia; DE FREITAS, Daniel Castanha. O pacto de San José da Costa Rica e a jurisprudência interamericana em matéria de direito à saúde. Revista do Direito, Santa Cruz do Sul, v. 1, n. 54, p. 205-225, jun. 2018.Disponível em:<https://online.unisc.br/seer/index.php/direito/article/view/11843/7331>. Acesso em: 29 mar. 2019. doi:http://dx.doi.org/10.17058/rdunisc.v1i54.11843. p. 208.

38 TRINDADE, Antonio Augusto Cançado. La protección internacional de los derechos económicos, sociales y culturales. In: CRUZ, R. C.; LOAIZA, R. N. Estudios básicos de derechos humanos. San José: IIDH, 1994, p. 3962. p. 49.

39 A afirmação decorre de análise realizada entre os anos de 2010 à 2017 no que toca à proteção de direitos de grupos em situação de vulnerabilidade, onde é possível extrair que das 18 (dezoito) decisões analisadas, 15 (quinze) ocorreram em um contexto ditatorial, sendo 8 (oito) delas referentes à tortura ou morte.

146 | Revista do Programa de Pós-Graduação em Direito da UFBA, e-issn 2358-4777, v. 30, n. 01, p.137 -150, Jan-Jun 2020 
civiles y políticos y derechos económicos, sociales y culturales fue el resultado de una decisión política de los Estados, que decidieron identificarlos de uno $u$ otro modo al adscribirlos a uno $u$ otro Pacto Internacional" ${ }^{40}$.O alcance extenso em termos de proteção que os direitos de ordem social possuem - guardando uma relação quase indissociável com reservas financeiras e custos ao Estado - configura-se, ainda, como um fator que dificulta a assunção destes pelos países.

É possível afirmar, também, especificamente em relação ao direito fundamental social à saúde, que nos casos em que o mesmo é tutelado, referida tutela de dá de forma reflexa ou indireta, como no Caso Ximenes Lopes versus Brasil ou em casos envolvendo a saúde de povos indígenas ${ }^{41}$. Ainda há, nesses termos, uma dificuldade quanto ao reconhecimento efetivo e expresso de casos envolvendo o direito à saúde no Sistema Interamericano de Proteção de Direitos Humanos.

Como sintetizam Piovesan e De Freitas ${ }^{42}$, algumas contribuições quanto à matéria são dadas pela Comissão e pela Corte Interamericana de Direitos Humanos, sendo responsabilidade internacional dos Estados:

a) a formação de políticas públicas direcionadas, capazes de atender parcela da população acometida por enfermidades específicas e garantir, com isso, a qualidade e a segurança do atendimento [...]; b) a maximização do acesso à saúde pública e, ao mesmo tempo, a garantia de universalidade no atendimento eficiente, respeitando-se as diferenças culturais dos destinatários das ações de saúde [...]; c) a implementação de medidas de saúde que alcancem especificamente os estabelecimentos de custódia, para que assegurem a promoção efetiva da saúde coletiva [...]; d) a elaboração de legislação e programas governamentais que conscientizem os cidadãos a respeito de seus direitos sociais, para que tomem decisões informados de todas as consequências das intervenções cirúrgicas, respeitada a diversidade cultural e a capacidade intelectual de cada indivíduo [...]; e) a investigação de falhas no aparato judicial e reformá-las, a fim de evitar dilações excessivas e prestigiar o princípio do devido processo legal e empregar eficiência ao Judiciário [...]; f) a promoção e disseminação da concepção contemporânea do direito à saúde, entendido como o direito humano ao desfrute do mais elevado nível possível de saúde física e mental.

Certo é que ainda há um longo caminho no reconhecimento do direito à saúde pelos Estados em termos internacionais, bem como no desenvolvimento jurisprudencial em termos de proteção e conceituação dos direitos de natureza econômica, social e cultural - que é característica marcante dos julgados da Corte Interamericana de Direitos Humanos.

CASTILLO, Mileya. Derecho internacional de los derechos humanos. Valencia: Tirant lo blanch, 2003. p. 56.

Outros exemplos dessa tutela indireta são os casos: Caso Gonzales Lluy y otros Vs. Ecuador; Caso Artavia Murillo y otros (Fecundación in Vitro) Vs. Costa Rica, Caso Suárez Peralta Vs. Ecuador e Caso I.V. Vs. Bolivia. PIOVESAN, Flávia. Proteção dos Direitos Humanos: uma Análise Comparativa dos Sistemas Regionais Europeu e Interamericano. In: VON BOGDANDY, A.; PIOVESAN, F.; ANTONIAZZI, M. M. Direitos Humanos, Democracia e Integração Jurídica: avançando no diálogo constitucional e regional. Rio de Janeiro: Lumen Juris, 2011. p. 625-662. p. 646.

42 PIOVESAN, Flavia; DE FREITAS, Daniel Castanha. O pacto de San José da Costa Rica e a jurisprudência interamericana em matéria de direito à saúde. Revista do Direito, Santa Cruz do Sul, v. 1, n. 54, p. 205-225, jun. 2018.Disponível em:<https://online.unisc.br/seer/index.php/direito/article/view/11843/7331>. Acesso em: 29 mar. 2019. doi:http://dx.doi.org/10.17058/rdunisc.v1i54.11843. p. 223.

147 | Revista do Programa de Pós-Graduação em Direito da UFBA, e-issn 2358-4777, v. 30, n. 01, p.137 -150, Jan-Jun 2020 


\section{Conclusão}

A judicialização da saúde consolidou-se como um fenômeno marcante do Estado Democrático Direito brasileiro, ressaltando o protagonismo judicial existente nos dias de hoje. A tutela judicial individualizada dos direitos fundamentais sociais contribuiu em grande medida para a crescente demanda de decisões envolvendo a concretização do direito à saúde, reforçando a existência de uma dimensão objetiva e de uma dimensão subjetiva dos mesmos. Ainda que existentes discussões sobre a aplicabilidade imediata dos direitos fundamentais sociais, a proteção constitucional destinada ao mesmo é inegável e vem sendo reforçada pela jurisprudência do Supremo Tribunal Federal.

Em termos internacionais, a proteção multinível de direitos humanos vem sendo substanciada pela Corte Interamericana de Direitos Humanos, por meio de mecanismos como o controle de convencionalidade, que pode ocorrer tanto na forma concentrada como difusa - a ser realizada pelos juízes nacionais. A realização deste controle pela Corte de San José é a via mais utilizada em termos de proteção externa de direitos fundamentais, reconhecidos como direitos humano em âmbito internacional.

Contudo, embora a assunção de compromissos internacionais quanto à proteção de direitos de natureza econômica, social e cultural, ainda é rasa e parca a jurisprudência da Corte IDH sobre a temática. Deste modo, é possível perceber uma diferença considerável em termos de judicialização do direito à saúde no Brasil e no Sistema Interamericano de Proteção, estando o fenômeno consolidado e em expansão em nível nacional e ainda em passos lentos em nível internacional.

\section{Referências}

ALCALÁ, Humberto Nogueira. El uso de las comunicaciones transjudiciales por parte de las jurisdicciones constitucionales en el derecho comparado y chileno. In: ALCALÁ, H. N.; ZELADA, L. G. Jurisprudencia del Tribunal Constitucional ante los derechos humanos y el derecho constitucional extranjero. Santiago: Librotecnia, 2014. p. 509-570.

2000.

Teoria de los derechos fundamentales y los derechos humanos. Montevideo: Ingranusi,

ALEXY, R.; SILVA, R. L. N. Direitos fundamentais sociais e proporcionalidade. In: ALEXY, R.; XAVIER, N. L.; SILVA, R. L. N. D. Dignidade humana, direitos sociais e não-positivismo inclusivo. Florianópolis: [s.n.], 2015. p. 165-178.

ARROYO, César Landa. Convencionalización del Derecho peruano. Lima: Palestra, 2016.

BARROSO, Luís Roberto. Constituição, democracia e supremacia judicial: direito e política no brasil contemporâneo. RFD- Revista da Faculdade de Direito- UERJ, Rio de Janeiro, v. 2, n. 21, jan./jun. 2012. 
BAZÁN, Víctor. El control de convencionalidad: incógnitas, desafíos y perspectivas. In: BAZÁN, Víctor; NASH, Claudio. Justicia Constitucional y Derechos Fundamentales: El control de convencionalidad. Colombia: Unión Gráfica Ltda, 2012. p. 17-55.

BRANDÃO, Rodrigo. Supremacia judicial versus diálogos constitucionais: a quem cabe a última palavra sobre o sentido da Constituição? Rio de Janeiro: Lumen Juris, 2012.

CASAL, María Angélica Benavides. El control de compatibilidad y el control de convencionalidad (o el problema de la competencia). Estudios Constitucionales: Revista del Centro de Estudios Constitucionales, Talca, Ano 15, no. 2. p. 365-388, 2017.

CASTILLO, Mileya. Derecho internacional de losderechos humanos. Valencia: Tirantloblanch, 2003.

CAVALLO, Gonzalo Aguilar. El juez estatal en la era del constitucionalismo de los derechos. In: LEAL, M. C. H.; ALVES, F. D. (Orgs.). Diálogos continentais sobre o controle de convencionalidade. Curitiba: Prismas, 2017.

CARVALHO, Mariana Siqueira de Carvalho. A Saúde como direito Social Fundamental na Constituição Federal De 1988. Revista de Direito Sanitário, Brasília - DF, v. 4, n. 2, jul. 2003.

FRIEDMAN, Barry. Dialogue and judicial review.The Michigan Law Review Association, Michigan, v. 91, p. 577-682, 1993.

GORCZEVSKI, Clovis. Direitos Humanos, Educação e Cidadania: conhecer, educar, praticar. 2. ed. Santa Cruz do Sul: Edunisc, 2016.

GRIMM, Dieter. Constitucionalismo y derechos fundamentales. Madrid: Trotta, 2006.

KRELL, Andreas Joachim. Realização dos direitos fundamentais sociais mediante controle judicial da prestação dos serviços públicos básicos (uma visão comparativa). Brasília, a. 36 n. 144 out./dez. 1999. p. 239-260.

LEDESMA, Eréndira Salgado. La problable inejecución de las sentencias de la Corte Interamericana de Derechos Humanos. Cuestiones Constitucionales: Revista Mexicana de Derecho Constitucional. México, 2012, p. 221-260.

MAAS, Rosana Helena Maas. O dever dos entes estatais de disponibilizar informações públicas como fundamento para o exercício do status activus processualis no controle de políticas públicas: uma proposta de canal de informação e transparência em políticas públicas da saúde (CITAPP saúde) frente ao estudo da judicialização da saúde em Santa Cruz do Sul. 2016. 289f. Tese (Programa de Pós-Graduação em Direito - Mestrado e Doutorado) - Universidade de Santa Cruz do Sul, Santa Cruz do Sul, 2016.

PIOVESAN, Flávia. Proteção dos Direitos Humanos: uma Análise Comparativa dos Sistemas Regionais Europeu e Interamericano. In: VON BOGDANDY, A.; PIOVESAN, F.; ANTONIAZZI, M. M. Direitos Humanos, Democracia e Integração Jurídica: avançando no diálogo constitucional e regional. Rio de Janeiro: Lumen Juris, 2011. p. 625-662. 
PIOVESAN, Flávia; DE FREITAS, Daniel Castanha. O pacto de San José da Costa Rica e a jurisprudência interamericana em matéria de direito à saúde. Revista do Direito, Santa Cruz do Sul, v. 1, n. 54, p. 205-225, jun. 2018.Disponível em:<https://online.unisc.br/seer/index.php/direito/article/view/11843/7331>. Acesso em: 29 mar. 2019. doi:http://dx.doi.org/10.17058/rdunisc.v1i54.11843.

PRADO, Ana Paula Barroso de Salles Paiva. Direito fundamental à saúde: direito social tratado como direito individual no Brasil. Tese (Mestrado em Direito) - Faculdade de Direito do sul de Minas. Pouso Alegre - MG. 2012.

RODRIGUEIRO, Daniela Aparecida; MOREIRA, José Cláudio Domingues. O direito social à saúde na perspectiva da constituição de 1988: um direito individual, coletivo e em construção. RIPE Revista do Instituto de Pesquisas e Estudos, Bauru, v.50, n.66, p.143-159, jul./dez. 2016.

STEIN, Flávia Thais; MORAES, Maria Valentina. Jurisdição constitucional e direitos fundamentais sociais: o problema da judicialização da saúde no município de Sobradinho. XIV Seminário Nacional de demandas sociais e políticas públicas na sociedade contemporânea \& IV Mostra nacional de trabalhos científicos. Universidade de Santa Cruz do Sul, 2018. Disponível em: < https://online.unisc.br/acadnet/anais/index.php/snpp/article/viewFile/17969/1192611938> Acesso em: 20 Ago. 2019.

TRINDADE, Antonio Augusto Cançado. La protección internacional de los derechos económicos, sociales y culturales. In: CRUZ, R. C.; LOAIZA, R. N. Estudios básicos de derechos humanos. San José: IIDH, 1994, p. 39-62.

USERA, Raúl Canosa. El Control de Convencionalidad. Pamplona: Aranzadi, 2015.

ZELADA, Liliana Galdámez. Jurisprudencia del Tribunal Constitucional ante los derechos humanos y el derecho constitucional extranjero. Santiago: Librotecnia, 2014. p. 509-570. 